\title{
Assessment of the Radioactive Contamination of the RBMK-1500 Reactor's Steam Pipelines and High Pressure Rings
}

\author{
G. Poškas $\mathbb{D}$, P. Poškas $\mathbb{D}$, and A. Šimonis \\ Lithuanian Energy Institute, Nuclear Engineering Laboratory, Breslaujos G. 3, Kaunas LT-44403, Lithuania \\ Correspondence should be addressed to G. Poškas; g.poskas@gmail.com
}

Received 23 October 2018; Accepted 7 February 2019; Published 3 March 2019

Guest Editor: Dimitrios Tsaoulidis

Copyright (C) 2019 G. Poškas et al. This is an open access article distributed under the Creative Commons Attribution License, which permits unrestricted use, distribution, and reproduction in any medium, provided the original work is properly cited.

Data analyses of radioactive contamination of the RBMK-1500 reactor's steam pipelines (SP) and components of high pressure rings (HPR) are presented in this paper. Also, modelled results of the SP-HPR system are compared to the results of other RBMK-1500 systems at Ignalina NPP Unit 1. Characteristics of SP-HPR components, thermal-hydraulic conditions of the coolant, and system operational regimes were evaluated employing the computer code LLWAA-DECOM (Tractebel Energy Engineering, Belgium). The presented results complement radiological characterization activities and facilitate the decommissioning process of nuclear facilities with RBMK type reactors. Analysis of the modelled results showed that the spread of radioactive contamination is very uneven between different components of the SP-HPR. The overall activity level of deposits of the SP-HPR is mostly determined by activated corrosion products and is lower than the activity level in the main circulation circuit (MCC) and nonpurified water subsystem activity of the purification and cooling system (PCS).

\section{Introduction}

The Ignalina NPP is the only nuclear power plant in Lithuania which was operating two Russian design RBMK-1500 type reactors. Unit 1 was commissioned in 1983 and Unit 2 in 1987. The original design lifetime was projected for up to 30 years; however, Unit 1 was shut down at the end of 2004 and Unit 2 at the end of 2009. At the moment, both units are under decommissioning. Such kind of reactors and their technological systems are under decommissioning for the first time in the world. Therefore, there is a lack of knowledge about the radioactive contamination of such kind of systems, especially about radionuclides important to decommissioning and disposal. Moreover, it is worldwide recognized that the radiological characterization is one of the key issues then planning for decommissioning of NPPs. Thorough radiological characterization ensures that proper safety measures are used to reduce personnel exposure, minimization of radioactive waste and optimal utilization of disposal facilities and also minimization of costs $[1,2]$.

Surface contamination of the systems' components with radioactive substances is a result of the contaminated coolant circulating within these systems. There are two mechanisms for the coolant in technological systems to be contaminated with radioactive substances: contamination by activated corrosion products and contamination by fission products and actinides [3].

Despite design and operational measures developed to reduce corrosion of the technological systems, corrosion products are released in kilogramme quantities per year into most water-cooled reactor circuits [4]. Corrosion rate is dependent on many factors, such as materials of components, coolant chemistry, flow regime, and temperature [5]. Corrosion products can be divided into soluble and particulate types and are involved in different transfer mechanisms between the coolant and the surface of systems' components [6]. Corrosion products are moved to the reactor core with the coolant and activated by neutron flux. This neutron activation is possible for both ions and particles. Activated corrosion products flow with the coolant to the reactor systems which are located outside of the core, where they deposit on the surfaces of the components and cause their surface contamination. The components located in the core corrode as well, and due to erosion, these radioactive particles are also transferred with the passing coolant to the systems located outside of the reactor core [7]. 
TABLE 1: Main SP-HPR components.

\begin{tabular}{lcc}
\hline No. & Name of the component & Marking \\
\hline 1 & Steam pipes from drum-separator to steam headers & SP-HPR-1 \\
2 & Steam headers & SP-HPR-2 \\
3 & Steam pipe between drum-separators & SP-HPR-4 \\
4 & Steam pipes to turbine & SP-HPR-5 \\
5 & Pipe to high pressure ring & SP-HPR-6 \\
6 & High pressure ring & SP-HPR-7 \\
7 & Inlet pipes of main steam relief valves and fast acting pressure reducing valve & SP-HPR-8 \\
8 & Pipe to steam reception chamber & \\
\hline
\end{tabular}

The fission process produces more than 200 radionuclides, either directly or indirectly by decay chains and in case of claddings defect, these fission products can be released from the fuel rods into the coolant and contaminate the systems outside of the core. Additionally, during manufacturing, the outer surfaces of the fuel rods might be contaminated with uranium oxide which in active zone will also form and release to the coolant fission products as well [8].

\section{Steam Pipelines and High Pressure Rings (SP-HPR)}

Steam pipelines (SP) and high pressure rings (HPR) ensure the removal of steam from the drum-separators to turbines and to accident localisation system, therefore protecting the main circulation circuit (MCC) against overpressure. The main SP-HPR components are listed in Table 1 and a simplified scheme is shown in Figure 1.

Steam by steam pipes (1) is supplied from two drumseparators to four steam headers (2) for one MCC loop. Steam from the middle of steam headers (2) via four main steam pipes (4) is supplied to the turbine. Steam from headers (2) via four steam pipes (5) is supplied to high pressure rings (6) and then via pipes (8) to the accident localisation system's (ALS) steam intake chambers if overpressure conditions are reached. In each $\mathrm{HPR}$, there are one fast acting reducing device (BRU-B valve) and six main steam relief valves (MSRV) installed.

\section{Methodology}

There is a number of complicated processes related to radioactive contamination of the systems described above. Therefore, when modelling the whole contamination process, it is necessary to consider such complicated processes as formation of radioactive particles, their deposition on surfaces, erosion of deposits and metal oxides, and transfer of particles by the flowing coolant. To analyse these processes in great detail, it is necessary to use complicated numerical solution models, which require time-consuming calculations even when the computational resources are relatively high. For this reason, in practice simplifications are made by implementing empirical and semi-empirical models in computer codes (PACTOLE [9], CRUDTRAN [10], ACE-II [11], CATE [12], etc.).
Assessment of the radioactive contamination of SP-HPR components listed in Table 1 was done employing LLWAADECOM computer code (Tractebel Energy Engineering, Belgium). The code is used to model the activity deposited on the surfaces of the components which is in contact with radioactive liquid or gaseous fluids. The code uses a set of modelling equations to estimate the Brownian diffusion velocity, the particle velocity in the coolant, probabilistic settling of particles, and the nuclides deposition and release rates. Its application is validated for the range of input parameters that is typical for nuclear reactors (turbulent flow of coolant, high Re numbers, appropriate nuclide list, etc.). Moreover, many codes are oriented towards evaluating activity of relatively short-lived nuclides which are important while reactor is still in operation; meanwhile, LLWAA-DECOM is intended for evaluating activity of waste considering decommissioning and disposal. The validation results of this code are presented in [13], where it is demonstrated that there is rather good agreement between the modelled and the measured results of dose rates and the deposits activity.

Specific activity of the deposits on the walls of the system components is described using the following equation [13]:

$$
\frac{d W_{i}}{d t}=K_{d} * C v_{i} *\left(1-f r s p r_{i}\right)-W_{i} *\left(K_{r}+\lambda_{i}\right)
$$

where $W_{i}$ is specific activity of $i$ th nuclide of deposits, $\left[\mathrm{Bq} / \mathrm{m}^{2}\right] ; K_{d}$ stands for particle deposition coefficient, $[\mathrm{m} / \mathrm{s}]$; $C v_{i}$ is specific activity of $i$ th nuclide of the coolant, $\left[\mathrm{Bq} / \mathrm{m}^{3}\right]$; frspr $_{i}$ is soluble part of $i$ th nuclide in the coolant; $K_{r}$ stands for particle relaxation coefficient, $\left[\mathrm{s}^{-1}\right] ; \lambda_{i}$ is decay constant of $i$ th nuclide, $\left[\mathrm{s}^{-1}\right] ; t$ is time.

Particle deposition and erosion ratio is described by complex deposition $\left(K_{d}\right)$ and relaxation coefficients $\left(K_{r}\right)$ for operation cycles of systems. These coefficients on their own are calculated taking into account the following aspects:

(i) particle speed because of Brownian forces and because of coolant flow velocity;

(ii) particle physical properties (diameter, density, and solubility);

(iii) coolant characteristics (temperature, viscosity, Reynolds number, average flow rate, and water $\mathrm{pH}$ );

(iv) parameters related to physical characteristics of system's components and operation characteristics of the system itself. 


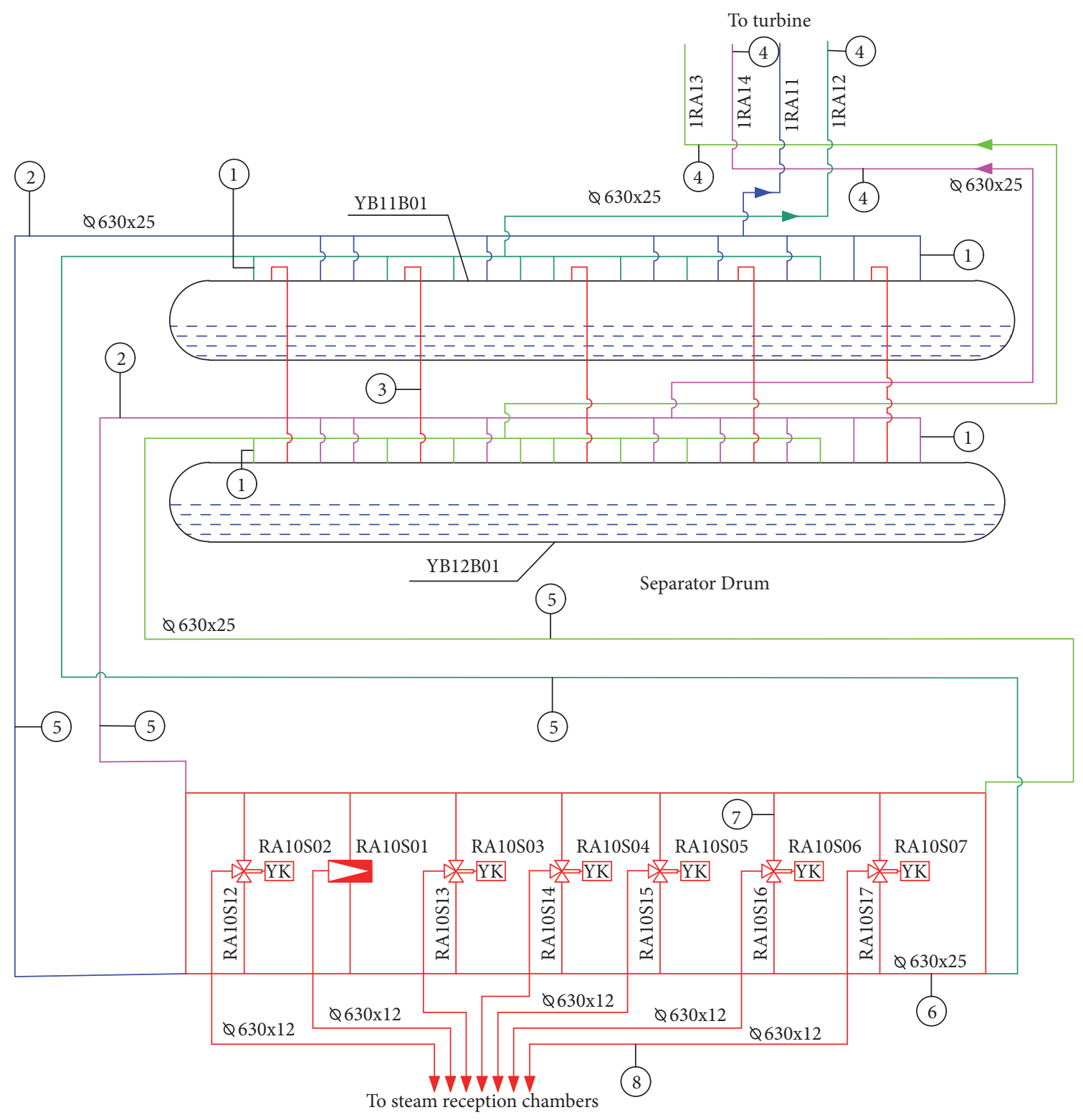

Figure 1: Simplified SP-HPR scheme.

In addition, local sensitivity analysis was performed for components with the highest contamination level to determine parameters that have the highest impact on uncertainty of the modelling results. Additional runs of the model with minimum ( $-20 \%$ of nominal value) and maximum $(+20 \%$ of nominal value) values of the parameters were necessary to perform such analysis. In total impact of 10 input parameters and volumetric activity of Co-60 and Fe-55 was analysed.

\section{Results}

Analysis of the modelling results on SP-HPR components' contamination shows (Figure 2) that steam pipes to the turbine (SP-HPR-4) and steam pipes from the drum-separator to headers (SP-HPR-1) with steam headers (SP-HPR-2) are the most contaminated components. The contamination of other components is much lower and comprises less than $1 \%$ of the contamination of the most contaminated component (SP-HPR-4).

Such variation in the activity of the deposits on the components is defined by different values of the relevant system operation, geometric, and coolant characteristics in the components of the system. There is no coolant filtration in this system, and therefore the average coolant activity is constant (an assumption that coolant is fully saturated during the operation cycle). The difference in the deposits of the components for the SP-HPR is mostly caused by the differences in coolant velocity. As stated in $[18,19]$, the particle deposition rate increases as the velocity of the coolant increases. This is related to the intensity of coherent structures near the wall. Turbulent fluctuations of the coolant flow increase, especially the normal component $\mathrm{v}^{\prime}$ of the turbulent 


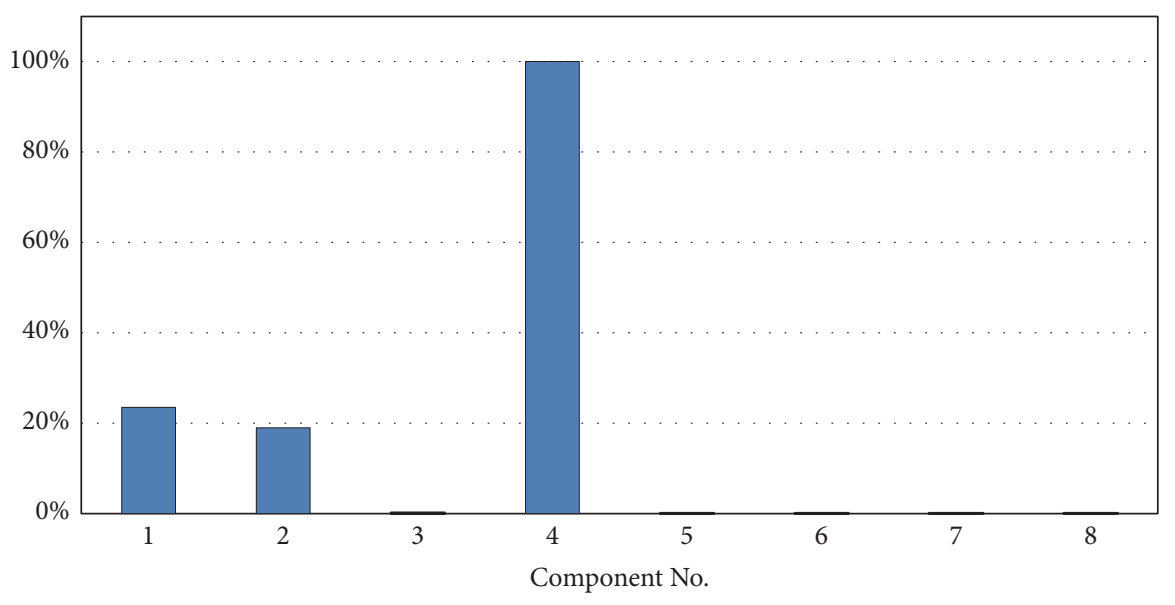

Relative component activity

FIGURE 2: Relative activity of deposits on SP-HPR components (SP-HPR-1:8/SP-HPR-4).

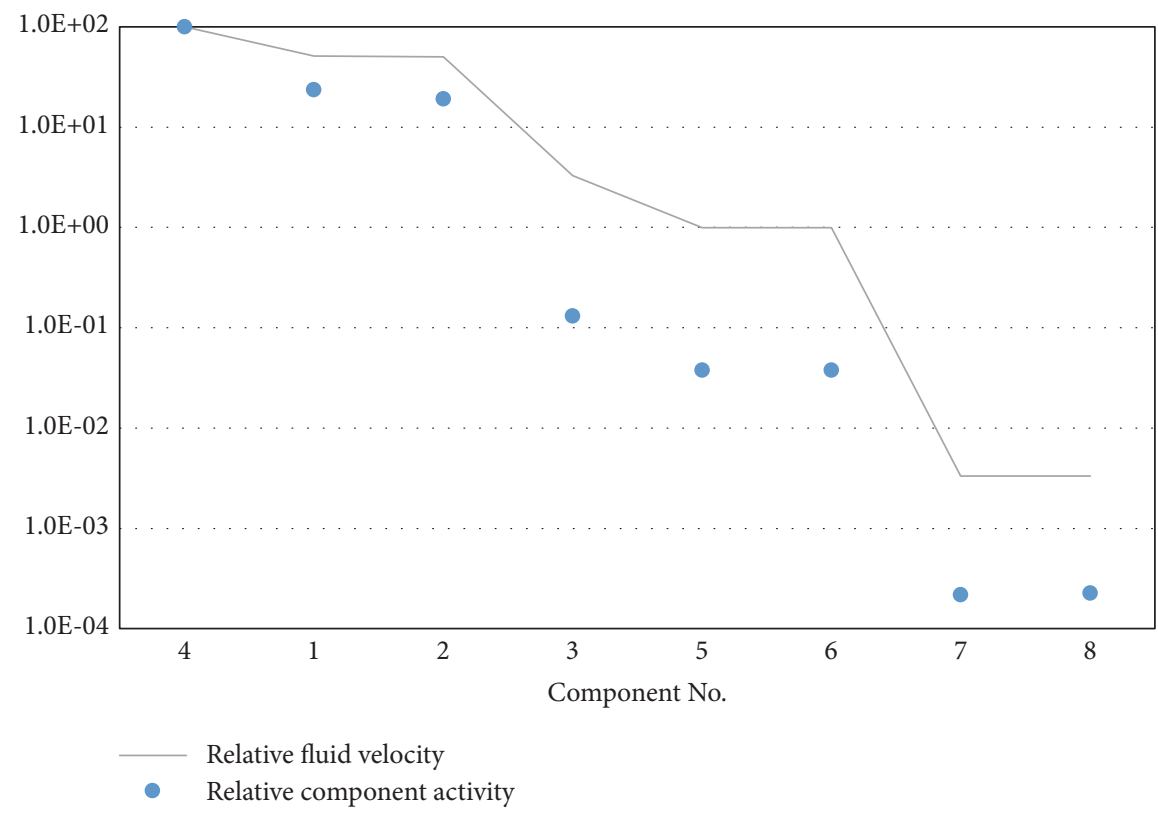

FIGURE 3: The interrelation between the contamination level and the coolant velocity.

flow, therefore increasing the particle transfer towards the walls. This dependency is also demonstrated in Figure 3. The contamination level is higher of those components in which the coolant flow velocity is higher. For instance, the average coolant velocity through SP-HPR-4, SP-HPR-1, and SP-HPR2 components is high and therefore increases the particle deposition rate.

The relative activity of radionuclides in the deposits is changing because of the radioactive decay process. Changes of the relative activity of radionuclides for the most contaminated component of SP-HPR are shown in Figure 4(a). At the final shutdown of the reactor, Fe-55, Fe-59, Mn-54, and Co-60 nuclides are dominant in the contamination of the SP-HPR. The long-lived nuclide Ni-63 is dominant in the deposits after 35 years since the short-lived radionuclides (Fe-55, Co-60, Mn-54, and Fe-59) decay in a short period of time. The activity of other long-lived nuclides remains practically unchanged, so their contribution to the total activity increases.

Nuclides that emit $\gamma$ radiation define the doses of direct irradiation to workers during dismantling of the system components. Changes of the radionuclides' relative impact to dose rate at the outer surface of the most contaminated component of SP-HPR are shown in Figure 4(b). At the final shutdown of the reactor, $\gamma$ radiation from the deposits on SP-HPR components is mostly determined by Mn-54, Co-58, Fe-59, and Co-60. But due to longer half-life, Co-60 is the most significant contributor to the total dose rate five years after 


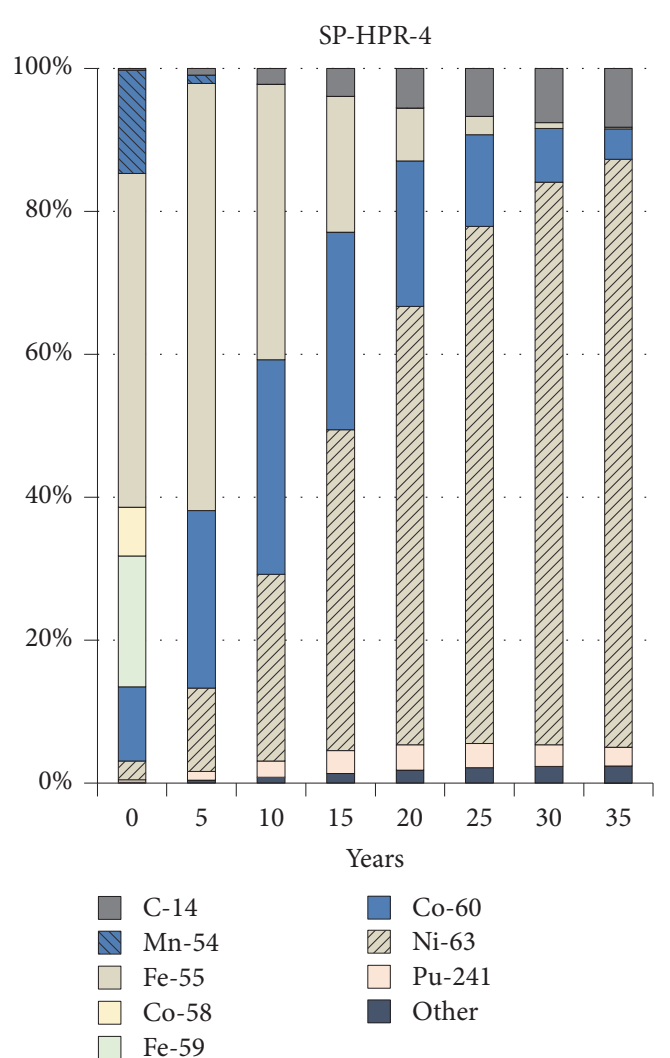

(a)

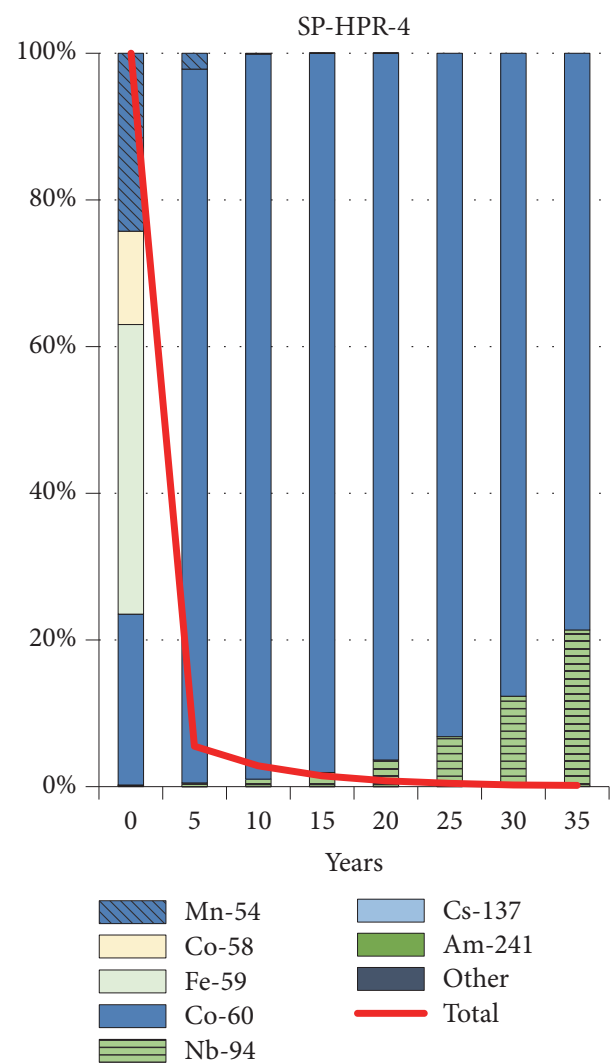

(b)

FIGURE 4: Changes of the relative composition of nuclides for SP-HPR-4 component with time: (a) activity of the deposits; (b) $\gamma$ dose rate of the deposits (other $<1 \%$ ).

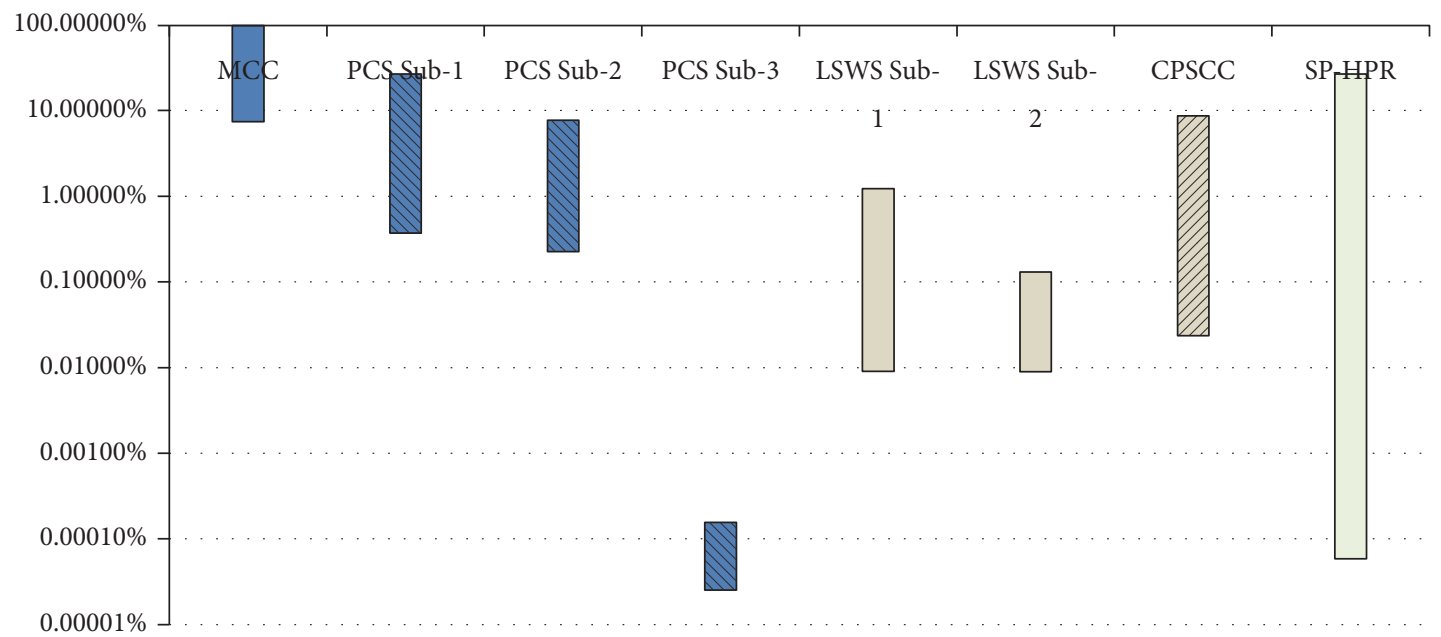

FIGURE 5: Comparison of relative deposit activity of SP-HPR, MCC [14], PCS [15], LSWS [16], and CPSCC [17] subsystems components compared to the MCC MCP activity (PCS-i:LSWS-i:CPSCC-i:SP-HPR-i / MCC pump).

the final shutdown. Moreover, the total dose rate decreases rapidly during the first 5 years (more than 90\%) due to the decay of short-lived radionuclides.

The scattering in the deposit activity ratio (at the final shutdown of the rector) between the most (the top of the bar) and the least (the bottom of the bar) contaminated components of the SP-HPR, MCC [14], PCS [15], LSWS [16], and CPSCC [17] systems compared to the activity of the MCC characteristic component (main circulation pump, $\mathrm{MCP}$ ) is presented in Figure 5. As is shown in the chart, the activity of SP-HPR is lower than that of MCC and PCS nonpurified water subsystem. It is noteworthy that the deposit activity 


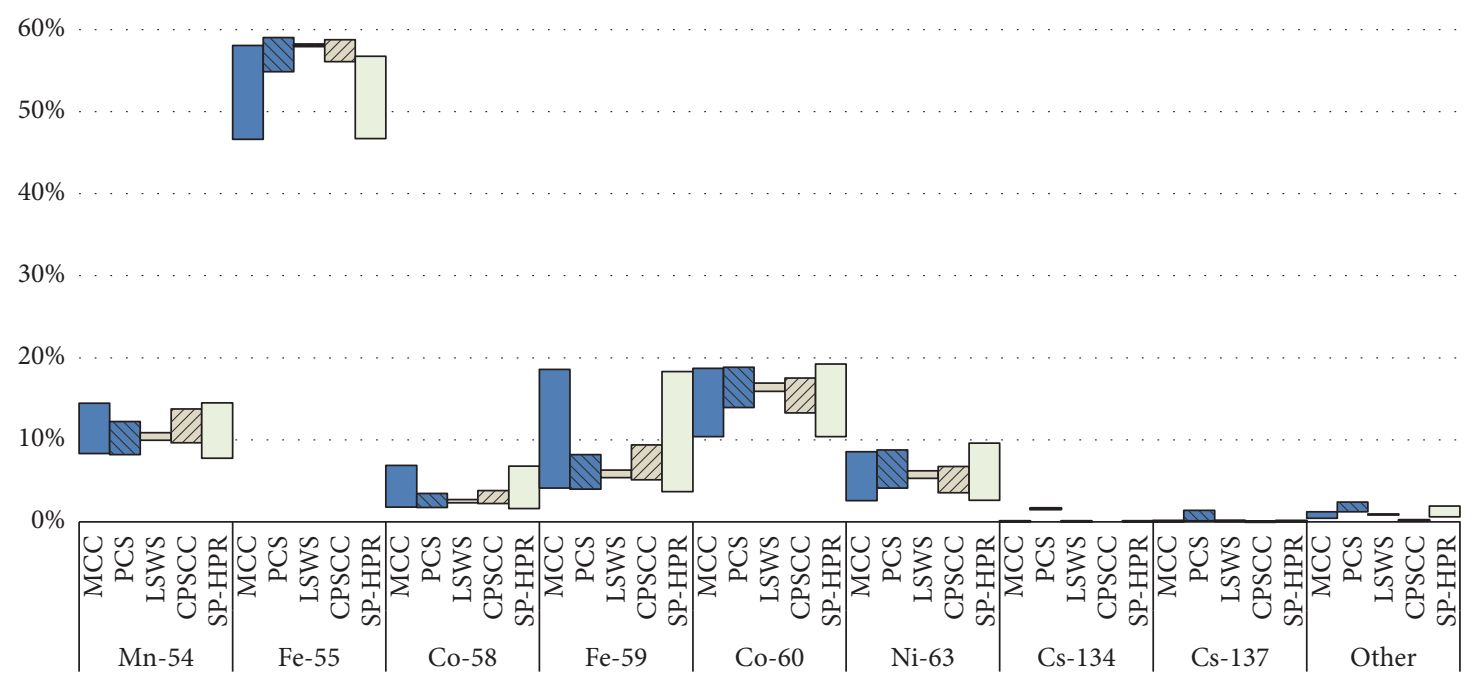

FIGURE 6: Relative activity of the radionuclides in the deposits of the systems of SP-HPR, MCC [14], PCS [15], LSWS [16], and CPSCC [17] subsystems $($ other $<1 \%)$.

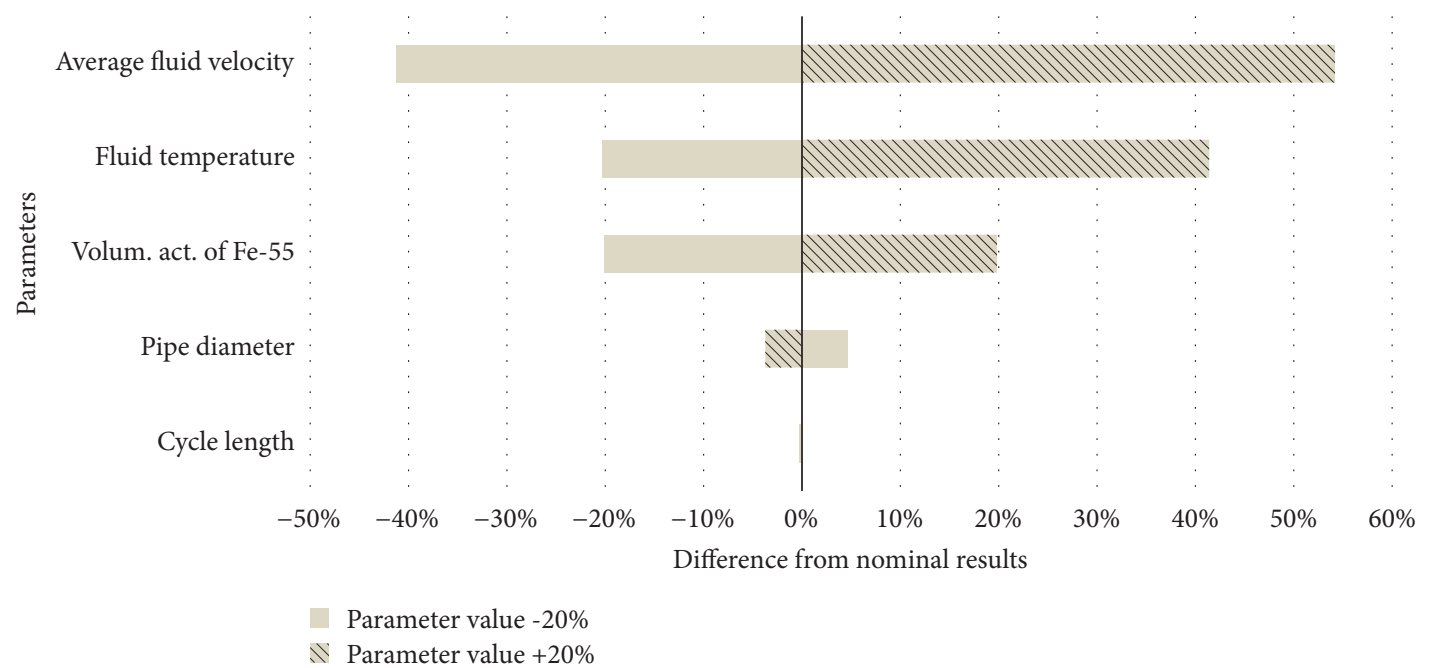

FIGURE 7: A tornado diagram presenting sensitivity analysis results of SP-HPR-4 component's contamination with Fe-55.

of SP-HPR system components is more scattered compared to other subsystems. This is because HPRs are considerably less contaminated than SPs. The most contaminated and the least contaminated components of SP-HPR constitute about $27 \%$ and less than one-tenth thousands of percent of activity, respectively, compared to the activity of the MCC MCP.

Scattering of relative deposit activity after final shutdown of the reactor for a specific radionuclide of the SP-HPR and other RBMK-1500 systems' components is shown in Figure 6. The top and the bottom of the bar represent maximum and minimum relative activity of a component's deposits per radionuclide and per system compared to the total deposit activity for those subsystem's particular components. The highest activity in deposits of the SP-HPR is caused by radionuclides generated from activation of corrosion products as in other systems chosen for comparison. Scattering of activity for SP-HPR components per radionuclide is similar as in the MCC. For both systems, the highest activity in deposits is from Fe-55: MCC $47 \%-58 \%$ and SP-HPR 47\%-57\% of total activity. Fission products (as Cs-134 and Cs-137) in smaller quantities are deposited on all systems' components (except CPSCC, which should not have nuclides that are generated during nuclear fuel fission or transmutation because contaminated water from this system does not mix directly with MCC water). The contribution of these radionuclides to the total activity is rather small (usually less than $1 \%$ ), so they are marked as "other".

Sensitivity analysis data on contamination of SP-HPR-4 component with Fe-55, which is the main contributor to the total activity at the reactor's final shutdown, are graphically presented in a tornado diagram (Figure 7). The parameters are presented in line with uncertainty importance on the deposits contamination. Uncertainty of average coolant velocity is the most important. Reduction of its value by $20 \%$ 


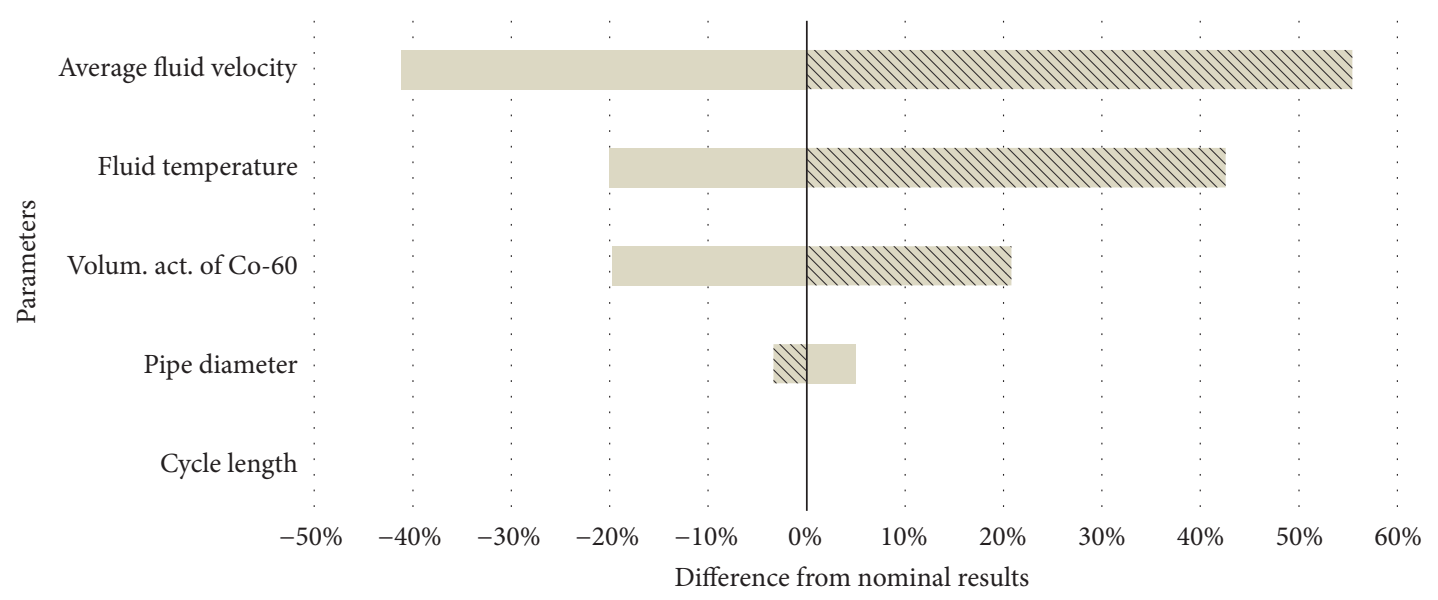

Parameter value $-20 \%$

N Parameter value $+20 \%$

FIGURE 8: A tornado diagram presenting results of the sensitivity analysis of SP-HPR-4 component's contamination with Co-60.

will give $40 \%$ decrease in the deposit contamination with Fe55 . Increase of the coolant temperature $\left({ }^{\circ} \mathrm{C}\right)$ parameter by $20 \%$ will result in increased deposit activity caused by $\mathrm{Fe}-55$ by about $54 \%$. Uncertainty of the activity of this radionuclide in coolant is also important. Uncertainty of pipe diameter and cycle length is not that important estimating the contribution of Fe-55 to the contamination of SP-HPR-4 component.

Figure 8 shows sensitivity analysis data of the deposits contamination with Co-60 of SP-HPR-4 component. Five years after the final shutdown of the reactor, Co-60 is the main contributor to the total dose. Similarly as with Fe-55, the uncertainty of average coolant velocity has the highest impact evaluating the SP-HPR-4 component's contamination uncertainty with Co-60. The velocity variation from $-20 \%$ to $+20 \%$ from the nominal value will result in $\sim 41 \%$ and $\sim 56 \%$ activity variation, respectively. Uncertainty of fluid temperature and Co-60 activity in the fluid are also of high importance, whereas uncertainties of the diameter of the pipe and the length of the cycle are not that important.

\section{Conclusions}

Component contamination of steam pipelines (SP) and high pressure rings (HPR) was modelled and analysed in this investigation. Modelling data were compared with the contamination results of other systems of the RBMK-1500 reactor. Based on this, the following conclusions have been drawn:

(1) Steam pipes to the turbine (SP-HPR-4) and steam pipes from the drum-separator to headers (SP-HPR1) with steam headers (SP-HPR-2) are the most contaminated components. Contamination of other components is much lower and comprises less than $1 \%$ of the contamination of the component with the highest level of contamination (SP-HPR-4) contamination.

(2) Just after the final shutdown of the reactor, $\gamma$ radiation from the deposits on SP-HPR components is mostly determined by Mn-54, Co-58, Fe-59, and Co-60. But due to longer half-life, Co-60 is the most significant contributor to the total dose rate five years after the final shutdown. Moreover, the total dose rate decreases rapidly during the first 5 years (more than $90 \%$ ) due to the decay of the short-lived radionuclides.

(3) Contamination of the SP-HPR system is lower in comparison with the main circulation circuit (MCC) and purification and cooling system's (PCS) nonpurified water subsystem, and activity scattering amongst the components of the SP-HPR is larger in comparison to other subsystems.

(4) Highest activity in deposits of the SP-HPR is caused by radionuclides generated from activation of corrosion products as in other RBMK-1500 systems. The highest activity in deposits is from $\mathrm{Fe}-55$, i.e., $47 \%-57 \%$ of total SP-HPR contamination.

(5) Sensitivity analysis results showed that the most important input parameters are average coolant velocity, coolant temperature, and volumetric activity in the coolant.
Abbreviations
ALS: Accident localisation system
HPR: High pressure rings
MCC: Main circulation circuit
MCP: Main circulation pump
PCS: Purification and cooling system
SP: $\quad$ Steam pipelines.

\section{Data Availability}

The main data used to support the findings of this study are included within the article. Detailed data used for modelling 
have not been made available because it is a commercial secret.

\section{Conflicts of Interest}

The authors declare that there are no conflicts of interest regarding the publication of this paper.

\section{References}

[1] "Radiological characterization of shut down nuclear reactors for decommissioning purposes," IAEA Technical Reports Series No. 389, 1998.

[2] Radiological Characterisation for Decommissioning of Nuclear Installations, OECD/NEA, Paris, France, 2013.

[3] "Modelling of transport of radioactive substances in the primary circuit of water-cooled reactors," IAEA Technical Reports Series No. 1672, 2012.

[4] G. Comley, "The significance of corrosion products in water reactor coolant circuits," Progress in Nuclear Energy, vol. 16, no. 1, pp. 41-72, 1985.

[5] V. G. Kritskii, Water Chemistry and Corrosion of Nuclear Power Plant Structural Materials, Russian Materials Monograph Series, American Nuclear Society, La Grange Park, Ill, USA, 1999.

[6] "Coolant technology of water cooled reactors: an overview," IAEA Technical Reports Series No. 347, 1993.

[7] M. Laraia, Nuclear Decommissioning: Planning, Execution and International Experience, M. Laraia, Ed., Woodhead Publishing Series in Energy, Woodhead Publishing, Philadelphia, PA, USA, 2012.

[8] B. J. Lewis and A. Husain, "Modelling the activity of 129I in the primary coolant of a CANDU reactor," Journal of Nuclear Materials, vol. 312, no. 1, pp. 81-96, 2003.

[9] P. Beslu, G. Frejaville, and A. Lalex, "21. A computer code PACTOLE to predict activation and transport of corrosion products in a PWR," in Water Chemistry of Nuclear Reactor Systems, pp. 195-201, Thomas Telford Publishing, 1978.

[10] J. S. Song, H. J. Cho, M. Y. Jung, and S. H. Lee, "A study on the application of crudtran code in primary systems of domestic pressurized heavy-water reactors for prediction of radiation source term," Nuclear Engineering and Technology, vol. 49, no. 3, pp. 638-644, 2017.

[11] K. A. Burrill and P. Menut, "A description of the activity transport computer codes in the iaea benchmarking exercise," in Water Chemistry of Nuclear Reactor Systems, vol. 8, pp. 519-526, Thomas Telford Publishing, 2001.

[12] J. Zhang, L. Li, S. He, and Y. Chen, "Calculation of radioactivity and dose rate of activated corrosion products in water-cooled fusion reactor," Science and Technology of Nuclear Installations, vol. 2016, Article ID 6051834, 6 pages, 2016.

[13] B. Lemens, B. Centner, P. Beguin, and K. Mannaerts, "Determination and declaration of critical nuclide inventories in Belgian NPP radwaste streams," in Proceedings of WM99 Conference, 1999.

[14] P. Poskas, R. Zujus, and A. Brazauskaite, "Preliminary radiological characterisation of the main circulation circuit at Ignalina NPP for decommissioning purposes," in Proceedings of WM'04 Conference, pp. 1-9, 2004.

[15] G. Poskas, R. Zujus, P. Poskas, and G. Miliauskas, "Modelling of the radiological contamination of the RBMK-1500 reactor water purification and cooling system," Science and Technology of Nuclear Installations, vol. 2014, Article ID 293158, 8 pages, 2014.

[16] G. Poskas, R. Zujus, and P. Poskas, "Analysis of the radiological contamination of the RBMK-1500 reactor low salted water system," Progress in Nuclear Energy, vol. 85, pp. 707-712, 2015.

[17] G. Poskas and R. Zujus, "Modelling of the radiological contamination of the RBMK-1500 reactor control and protection system channels' cooling circuit," World Journal of Engineering and Technology, vol. 03, no. 03, pp. 1-5, 2015.

[18] M. Reck, P. S. Larsen, and U. Ullum, "Particle deposition in lowspeed, high-turbulence flows," Atmospheric Environment, vol. 36, no. 30, pp. 4801-4809, 2002.

[19] A. Dehbi, "Assessment of a new fluent model for particle dispersion in turbulent flows," in Proceedings of the Workshop on Benchmarking of CFD Codes for Application to Nuclear Reactor Safety (CFD4NRS), 2006. 

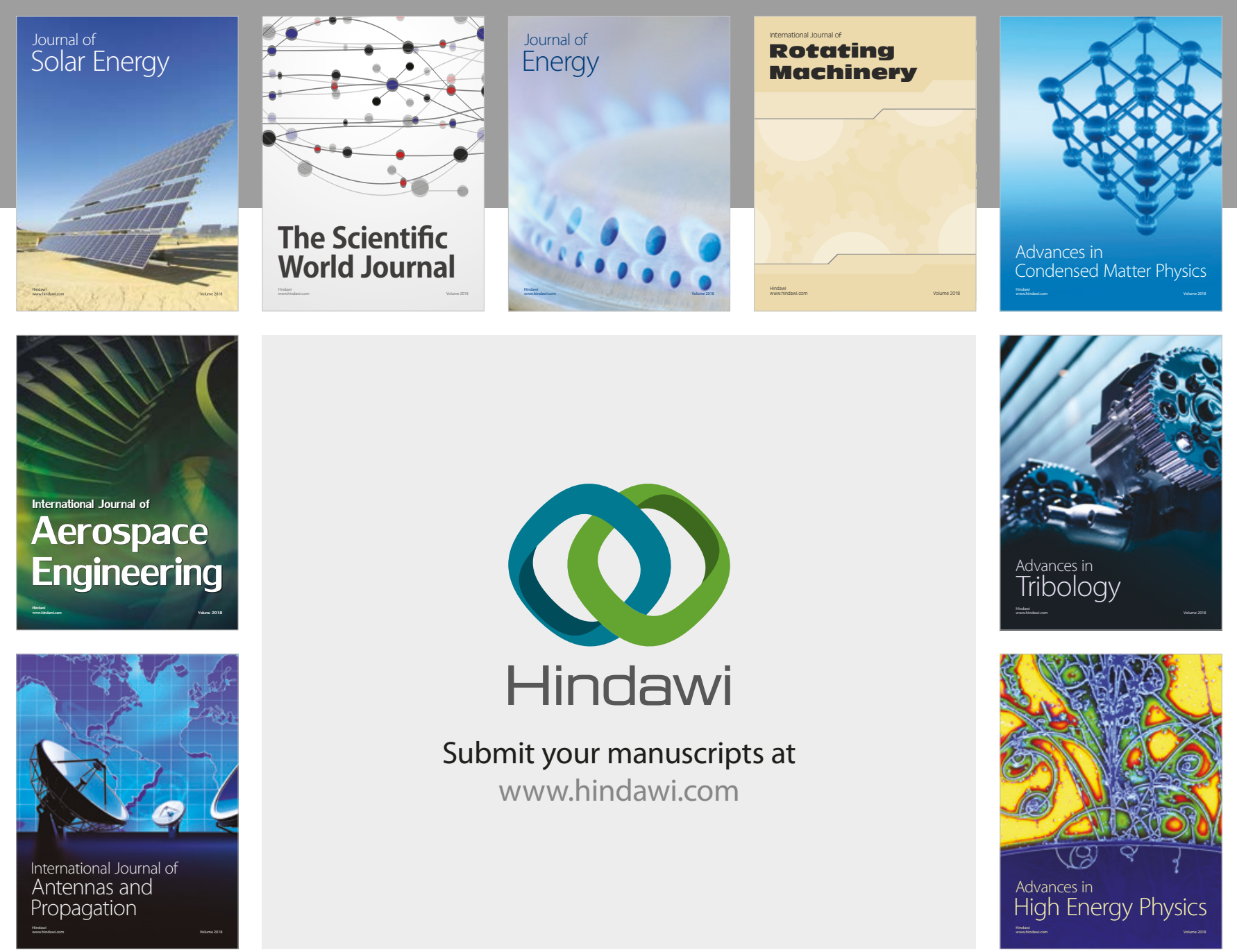

Submit your manuscripts at

www.hindawi.com
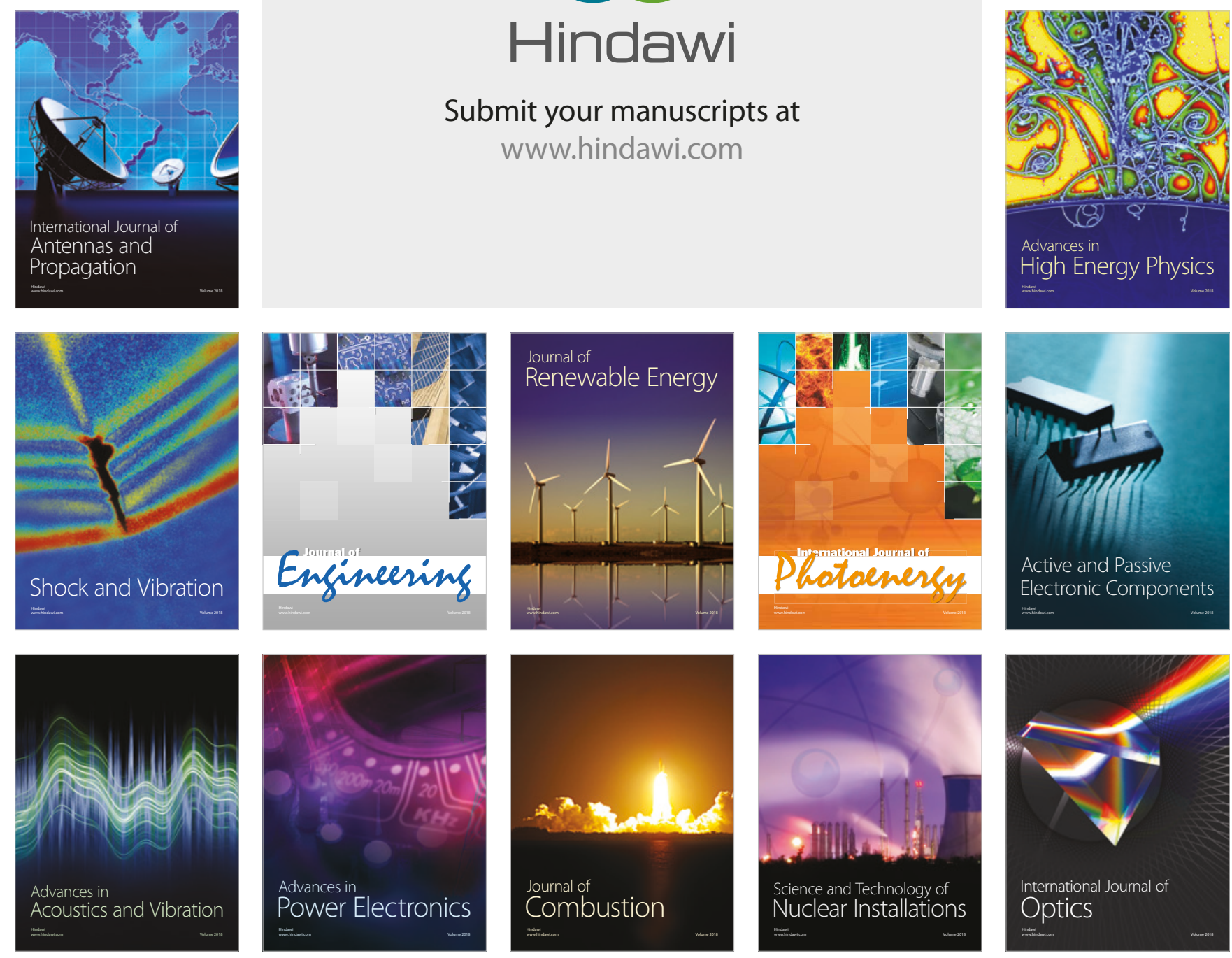